\title{
Impact of the Art of Living Programme on Burnout and Organizational Role Stress among Animal Husbandry Personnel
}

\author{
Subhash R Soni ${ }^{1 *}$, Vyas $\mathrm{JM}^{1}$, Pestonjee $\mathrm{DM}^{2}$, Kher $\mathrm{HN}^{3}$, Thakkar KA ${ }^{3}$ and Vijaya Lakshmi Yanduri ${ }^{4}$ \\ ${ }^{1}$ Gujarat Forensic Sciences University Gandhinagar, Gujarat, India \\ ${ }^{2}$ School of Petroleum Management, India \\ ${ }^{3}$ Sardarkrushinagar Dantiwada Agricultural University, India \\ ${ }^{4}$ District Institute of Education and Training, India
}

\begin{abstract}
Objective: To assess the impact of the Art of Living programme on Burnout and Organizational Role Stress (ORS) by systematic application of powerful ancient techniques of meditation, yoga, sudarshan kriya and breathing techniques on group of people among Animal Husbandry Personnel.
\end{abstract}

Setting: Eight districts of Gujarat state, India.

Design: Descriptive cross-sectional.

Subjects: Two hundred and thirty six (236) Veterinarians and One hundred and forty six (146) Paraveterinarians of Animal Husbandry Department.

Outcome measures: The findings relate to the status of Burnout and ORS factors in case of Veterinarians and Paraveterinarians of Animal Husbandry Department. The findings also assess the changes in burnout and organizational role stress before and after the intervention.

Methods: The Pareek's Occupational Stress scale and Maslach Burnout scale (MBI-GS) were used for data collection, while central tendencies, frequency, t-test, Co-efficient of Correlation (' $r$ ') were used for statistical analysis. The data were collected two times, i.e. pre and post intervention.

Results: The data revealed that majority of veterinarians and paraveterinarians were having high Organizational Role Stress and low level of exhaustion and cynicism ( 50\%). The Organizational Role Stress varied for different role stresses in the range of $40 \%$ to $77 \%$ except Self Role Distance (SRD) which reduced to a considerable extent after the Art of Living program on Meditation, Sudarshan Kriya and Breathing Techniques. The percentage increased for lower category after the Art of Living programme. The personal efficacy increased in both the categories of the employees from $46 \%$ to $65 \%$ and $48 \%$ to $63 \%$ in the case of veterinarians and para veterinarians, respectively. Further, significant difference between pre and post score was observed in case of all three burnout sub-scales viz., Exhaustion, Cynicism and Personal Efficacy.

Conclusion: It could be concluded that the Art of Living Program through Meditation, Sudarshan Kriya and Breathing Techniques had a significant impact on reducing all Organizational Role Stress and Burnout. The findings lead us to the unmistakable conclusion that Art of Living programme when conducted under proper environment have a salutary beneficial impact on organizational wellbeing of the individual.

Keywords: Veterinarians; Para veterinarians; The art of living programme; Organizational role stress; Exhaustion; Cynicism; Personal efficacy and burnout

\section{Introduction}

Stress becomes a universal feature of life and no one can live without experiencing some degree of stress. As a result, stress related diseases and syndromes are becoming very common today. The pressure of balancing the work life and non-work life is also at peak. This also often results in increasing stress and burnout among the employees. Stress has been considered as one of the major factors in work organization [1]. Sources of stressors in the employment organization are work, role, personal development, interpersonal relations and organization climate [2]. The role ambiguity, role isolation, role overload, role erosion and overall role stress had a detrimental effect on all aspects of job satisfaction and morale [3]. The organizational role stress, dimensionwise as well as total, was highly inter-correlated [4]. The spectrum of studies reviewed relating to extent of burnout among human service professionals, including teachers, doctors and nurses churn out a considerable variation across different professions and within the same profession [5-12]. The animal husbandry sector which is potentially one of the most important sectors of rapid socio-economic development of Gujarat State, India, is also not exceptional to this. The veterinary and animal science service is a highly specialized area that involves tasks like management and health care of the livestock and poultry, prevention of diseases, disease diagnosis etc. Also, Globalization and implementation of world trade agreements (WTA) has increased the scope for export of livestock and hygienically produced livestock products manifolds. Movement of livestock and livestock products across the borders also introduces the risk of trans-boundary infections. Zoonotic diseases and

*Corresponding author: Subhash R Soni, Gujarat Forensic Sciences University Gandhinagar, Gujarat, India, Tel: 91 9978406331; Fax: 91 66739028; E-mail: madhuspl@yahoo.com

Received February 20, 2015; Accepted April 21, 2015; Published April 30, 2015

Citation: Soni SR, Vyas JM, Pestonjee DM, Kher HN, Thakkar KA, et al. (2015) Impact of the Art of Living Programme on Burnout and Organizational Role Stress among Animal Husbandry Personnel. J Psychiatry 18: 288 doi: 10.4172/2378-5756.1000288

Copyright: ( 2015 Soni SR, et al. This is an open-access article distributed under the terms of the Creative Commons Attribution License, which permits unrestricted use, distribution, and reproduction in any medium, provided the original author and source are credited 
public health issues associated with livestock and livestock products are other concerns. In this context, the role of the veterinarians and paraveterinarians of Animal husbandry Department has become multifaceted as a clinician, researcher, and an advisor. In order to manage these multi-dimensional activities, there is a high need of qualified technical manpower and facilities. However, shortage of technical manpower and poor veterinary infrastructure is affecting quality of manpower and services. The main duties of these cadres include organizing animal health camps at village level; provide animal health care service at the door step; preventive as well as curative service delivery such as vaccination and educating animal keepers. The factors contributing to burnout syndrome and ORS among veterinarians and paraveterinarians include boredom, physical working conditions, time pressure and deadlines, work demands, critical decision making in emergency situations, over expectations of people, job design and technical problems. Under such conditions, the employees of animal husbandry department are undervalued and under-appreciated in the society. The veterinarians and paraveterinarians are confronted with heart-breaking and frightening conditions that make them angry, frustrated, and hopeless. We observed the following symptoms among these employees: loss of interest in service, aggressive behavior, aloofness, absenteeism, lack of satisfaction for stake holders, decreasing productivity and production, lack of dedication and timely appropriate response, increasing complaints about professional service delivery and avoidance of responsibility. Overall the morale of the employees appeared down. There are many institutes working for the holistic development of human potentials including spiritual organizations which can easily manage or reduce the stress. Among these institutions, the Art of Living foundation's claims are more eye catching as it has, with its effective interventions, reached across the majority of the nations around the globe. The Art of Living Foundation uses the multiple techniques such as Sudarshan Kriya, Pranayama, Ujjai Breaths- a deep rhythmic breathing, Meditation, Yoga, Spiritual Games, Ego bursting process, Simple but profound knowledge tips for the well-being of the organizational as well as family life, etc. during its programme. This programme is well known around the globe as the Art of Living Happiness programme. The Art of Living foundation established in 154 countries. Organizational role stress and burnout play an important role in efficiency of the employees' performance in any organization. Sudarshan Kriya and Pranayama (SK and P) was effective in treating mild and melancholic depression. Significantly lower levels of blood lactate and higher levels of SOD, glutathione and catalyze were found in practitioners as compared to non-practitioners of Sudarshan Kriya [13]. Significant increase in beta activity in the left frontal, parieto-occipital and midline regions of the brain observed in the SK and P practitioners. It is suggestive of increased mental focus/ heightened awareness, mental alertness (beta activity). Reduction in stress-hormone levels (cortisol and ACTH) along with BDI reductions possibly supported a biological mechanism of SK and $\mathrm{P}$ in producing beneficial effects. They also found that statistically significant reduction in anxiety and improvement in stress coping skills. Janakiramaiah and Gangadhar, suggested that participants in the SK and P group, but not the control group, lowered their degree of anxiety, depression and stress, and also increased their degree of optimism [14]. However, the persons having history or symptoms of psychosomatic, psychotic, personality disorder and certain conditions such as pregnancy and physical disabilities need special care and attention before and during the intervention, the Art of Living programme. If due care is not taken for such class of persons, negative or harmful consequences may occur during the intervention. There is no research work available on burnout syndrome as well as organizational role stress (ORS) among these employees. It was deemed fit to investigate the ORS and burnout level among these cadres and to provide intervention. A detailed discussion was held with the regional Joint Director, Animal Husbandry Department and mutual agreement arrived at with him. It was decided to undertake stress audit of these employees of the department with ORS scale and MBG-GS inventory along with certain informative questionnaire about demographic variables and provide them intervention in the form of the Art of Living programme at the Art of Living Ashram near Vasad, District Anand, Gujarat, India during September, 2012 by the corresponding researcher.

\section{Objectives of the study}

- To study the organizational role stress and burnout among veterinarians and paraveterinarians (animal husbandry personnel).

- To study the relationship between organizational role stress and burnout among veterinarians and paraveterinarians.

- To study the impact of the Art of Living Programme on organizational role stress and burnout among veterinarians and paraveterinarians.

\section{Hypotheses}

Based on the objectives of the study and theoretical framework, the following statistical hypotheses were formulated as per the procedure recommended by Kerlinger [15].

1. There is no significant relationship between organization role stress and burnout among veterinarians and paraveterinarians working in Gujarat State.

2. There is no impact of the Art of Living Programme on organization role stress and burnout among veterinarians and paraveterinarians working in Gujarat State.

\section{Data and Method}

\section{Area of study}

Out of 26 districts of Gujarat state, eight districts, namely, Banaskantha, Gandhinagar, Sabarkantha, Ahmedabad, Mahesana, Kheda, Patan and Aanad were purposively covered under the study as the employees of these districts participated in the Art of Living programme.

\section{Sample of the study}

It was decided to study the whole population, but the respondents who were interested and joined for the intervention were taken as sample. A total of 236 out of 254 veterinarians attended and responded to the study. Whereas, 146 out of 376 paraveterinarians attended and responded to the study leading to the total sample size 382 . The sample size was about $61 \%$ of the universe. The inclusion criteria are voluntary participation among these two groups in animal husbandry department. Private practitioners, employees of co-operative sector and retired practitioners were not included in the study being exclusion criteria as they are not governed by the same rules and do not serve under similar service conditions.

\section{Tools for data collection}

The selection of variables included in the study was done based on an extensive review of literature, consultation with guide, experts and from previous studies taken-up on the related subjects. Following 
Citation: Soni SR, Vyas JM, Pestonjee DM, Kher HN, Thakkar KA, et al. (2015) Impact of the Art of Living Programme on Burnout and Organizational Role Stress among Animal Husbandry Personnel. J Psychiatry 18: 288 doi: 10.4172/2378-5756.1000288

Page 3 of 11

independent and dependent variables, which were considered to be the most relevant, were selected for the present investigation.

\section{Dependant variables:}

Organizational Role Stress scale (ORS Scale): The Organizational Role Stress (ORS) which is a standardized scale developed by Dr. Udai Pareek [16] was used to assess the level of role stress factors among the veterinarians and paraveterinarians. The ORS is divided into following 10 different role stress factors as indicated in Table 1 . The scale has total 50 items which are distributed equally for each of these Role Stresses. The subjects are required to respond on five point scales ranging from " 0 " to " 4 " indicating how much true a particular statement is for their role (Table 1). The placement of respondents in high, medium and low categories of organizational role stress among the employees depends upon the above range of scores on organizational role stress dimensions.

Burnout Sub-Scale: To study the burnout phenomenon, the MBI - General Survey or MBI-GS developed by Maslach et al. was used [17]. The MBI-GS provides a three dimensional perspective on burnout. Burnout is divided into following three different sub scales:

Exhaustion (EX): Which has references to fatigue.

Cynicism (CY): Reflects indifference or a distant attitude towards work as a way of coping with exhausting demands.

Personal Efficacy (PE): Includes satisfaction with past and present accomplishment; it explicitly assesses an individual's expectations of continued effectiveness at work.

A high degree of burnout is reflected in high scores on Exhaustion and Cynicism and low scores on professional efficacy. The respondents based on three sub-scales of burnout were classified into three categories viz., high, medium and low. The scoring pattern on each item of burnout inventory is on a seven point continuum form 0 which corresponds Frequency of Feeling "never" to 6 (six) which corresponds Frequency of Feeling "every day". The possible range of score on Exhaustion, Personal Efficacy and Cynicism is 0 to 30,0 to 36 and 0 to 30 , respectively (Table 2). The placement of respondents in high, moderate and low categories of burnout among the employees depends upon the following range of scores on the subscales.

Independent demographic variables: A separate sociodemographic data namely Gender, Age, Marital Status, Level of Education, Monthly Income, Position in Organization and Length of Service were used as independent demographic variables.

\section{Research design}

\begin{tabular}{|c|c|c|c|c|}
\hline Sr. No & Organizational role stress & Low & Medium & High \\
\hline $\mathbf{1 .}$ & Inter Role Distance (IRD) & 0 to 2 & 3 to 7 & 8 to 20 \\
\hline $\mathbf{2 .}$ & Role Stagnation (RS) & 0 to 2 & 3 to 7 & 8 to 20 \\
\hline $\mathbf{3 .}$ & Role Expectation Conflict (REC) & 0 to 2 & 3 to 6 & 7 to 20 \\
\hline $\mathbf{4 .}$ & Role Erosion (RE) & 0 to 7 & 8 to 11 & 12 to 20 \\
\hline $\mathbf{5 .}$ & Role Overload (RO) & 0 to 1 & 2 to 5 & 6 to 20 \\
\hline $\mathbf{6 .}$ & Role Isolation (RI) & 0 to 3 & 4 to 8 & 9 to 20 \\
\hline $\mathbf{7 .}$ & Personal Inadequacy (PI) & 0 to 2 & 3 to 7 & 8 to 20 \\
\hline $\mathbf{8 .}$ & Self-Role Distance (SRD) & 0 to 3 & 4 to 8 & 9 to 20 \\
\hline $\mathbf{9 .}$ & Role Ambiguity (RA) & 0 to 1 & 2 to 6 & 7 to 20 \\
\hline $\mathbf{1 0 .}$ & Resource Inadequacy (RIN) & 0 to 2 & 3 to 7 & 8 to 20 \\
\hline
\end{tabular}

Table 1: Organizational Role Stress scores.

\begin{tabular}{|c|c|c|c|c|}
\hline Sr. No & Frequency & Professional Efficacy & Exhaustion & Cynicism \\
\hline $\mathbf{1 .}$ & High & 30 or more & 16 or over & 13 or over \\
\hline $\mathbf{2 .}$ & Moderate & $24-29$ & $8-15$ & $6-12$ \\
\hline $\mathbf{3 .}$ & Low & $0-23$ & $0-7$ & $0-5$ \\
\hline
\end{tabular}

Table 2: Burnout sub scale scores.

The present study was confined to pre-test and post-test research design. The respondents were personally interviewed twice i.e., before conducting the Art of Living programme and after completion of the Art of Living programme.

\section{Methods used for data collection}

The basic method used in collecting data was through interview and validated psychometric instruments such as ORS scale and MBIGS inventory and for collecting the data on demographic inventory were used. For this purpose, the head of region i.e., Joint Director of Animal Husbandry Department was contacted and aims and objectives of the study were discussed. The employees gathered at a single place and the questionnaires and inventories were distributed and necessary instructions for their administration were given. The employees were assured of their secrecy and confidentiality that the data will be used only for the research purposes.

\section{Details of the intervention (the art of living programme)}

On completion of the responses to the research tools, the employees were provided the exposure to the Art of Living Programme. This programme was of five consecutive days from Wednesday to Sunday, distributed in seven sessions, each session was of three to four hours. The following contents were included in the programme: 1) Theory and practice of Yogasanas; 2) Importance of breaths and practice of Ujjai breath; 3) Theory and practice of Pranayama; 4) chanting of ॐั(Aum), a sacred mantras; 5) Sudarshan Kriya or healing breath Technique; 6) Importance of meditation and practice of three different meditations; 7) Important knowledge points involving different aspects of organizational and personal life; 8) Certain Questions and answers clarifying the basic concept of organizational and personal life; 9) Life force energy and its sources; 10) Melodious divine songs with music; 11) Knowledge on levels of human existence; 12) Sharing of experience; 13) Schedule of daily practice (home going instructions).

\section{Post programme data collection}

On completion of the intervention, the employees were again asked to respond to the same tools i.e., ORS scale and the MBI-GS inventory. The said data were also collected in person.

\section{Statistical frame work for analysis of the data}

Keeping in view the scope and objectives of the present investigation and for the interpretation and drawing inferences, the following statistical methods were used in the present study after performing the normality test on the data. The data was analyzed using the Statistical Package for Social Sciences (SPSS). As the data are normally distributed, the detail formulae applied for calculating parametric statistical computation are as under.

Frequency distribution and Measures of central tendencies: Frequency distribution, simple averages and percentage methods was extensively used to analyze the data. Mean score and standard deviation were calculated for finding out different values and was used 
Citation: Soni SR, Vyas JM, Pestonjee DM, Kher HN, Thakkar KA, et al. (2015) Impact of the Art of Living Programme on Burnout and Organizational Role Stress among Animal Husbandry Personnel. J Psychiatry 18: 288 doi: 10.4172/2378-5756.1000288

Page 4 of 11

for classification of the respondents into different categories.

Paired ' $t$ ' test: The Paired ' $t$ ' test was used to compare the data before and after the intervention (The Art of Living Programme) with regard to ORS and burnout. The ' $t$ ' value for each ORS and burnout sub-scale was calculated for comparing before and after score.

'P' Value: 'P' values were calculated to compare the data before and after the intervention (The Art of Living Programme) with regard to ORS and burnout. The 'P' value for each ORS and burnout sub-scales were calculated for comparing before and after score.

Co-efficient of Correlation (' $\mathbf{r}$ '): It is the measurement of association between two dependent variables. The coefficients of correlation were computed to find out the relationship between each of the ORS and burnout sub scales by employing the formula for calculation of Pearson's product moment correlation co-efficient.

\section{Results}

\section{Demographic characteristics}

Inventories were selected on the basis of the objectives of the study along with some demographic variables. Since the respondents were highly educated, questionnaire was considered to be the most suitable instrument for the data collection. The demographic characteristics schedule consisted information of the animal husbandry personnel regarding age, qualification, experience, position, income and marital status. The data regarding demographic characteristics is presented in Table 3. It can be inferred from this table that nearly two-fifth of the respondents $(60.7 \%)$ had education of graduation level, having above 21 years of service experience $(62.0 \%)$ with monthly income

\begin{tabular}{|c|c|c|c|c|c|}
\hline \multirow{3}{*}{$\begin{array}{c}\text { Sr. No. } \\
1 .\end{array}$} & \multirow{3}{*}{$\begin{array}{c}\text { Character } \\
\text { Position }\end{array}$} & \multicolumn{2}{|r|}{ Category } & \multirow{2}{*}{\begin{tabular}{|c|} 
Frequency \\
236
\end{tabular}} & \multirow{2}{*}{\begin{tabular}{|c|} 
Per cent \\
61.8
\end{tabular}} \\
\hline & & (i) & Veterinarian & & \\
\hline & & (ii) & Para veterinarian & 146 & 38.2 \\
\hline \multirow{3}{*}{2.} & \multirow{3}{*}{$\begin{array}{l}\text { Level of } \\
\text { education }\end{array}$} & (i) & Under-Graduate & 122 & 31.9 \\
\hline & & (ii) & Graduate & 232 & 60.7 \\
\hline & & (iii) & Post-Graduate and Above & 28 & 7.3 \\
\hline \multirow{7}{*}{3.} & \multirow{7}{*}{$\begin{array}{c}\text { Length of } \\
\text { service } \\
\text { (Experience) } \\
\text { years }\end{array}$} & (i) & 0 to 5 & 44 & 11.5 \\
\hline & & (ii) & 6 to 10 & 23 & 06.0 \\
\hline & & (iii) & 11 to 15 & 65 & 17.0 \\
\hline & & (iv) & 16 to 20 & 13 & 03.4 \\
\hline & & (v) & 21 to 25 & 118 & 30.9 \\
\hline & & (vi) & 26 to 30 & 52 & 13.6 \\
\hline & & (vii) & Above 30 & 67 & 17.5 \\
\hline \multirow{4}{*}{4.} & \multirow{4}{*}{$\begin{array}{l}\text { Monthly } \\
\text { income } \\
(\mathrm{Rs} /-)\end{array}$} & (i) & Up to 10,000 & 32 & 08.4 \\
\hline & & (ii) & $10001-20000$ & 27 & 07.1 \\
\hline & & (iii) & $20001-50,000$ & 266 & 69.6 \\
\hline & & (iv) & Above 50,000 & 57 & 14.9 \\
\hline \multirow{9}{*}{5.} & \multirow{9}{*}{$\begin{array}{l}\text { Age (in } \\
\text { years) }\end{array}$} & (i) & 21 to 25 & 02 & 00.5 \\
\hline & & (ii) & 26 to 30 & 40 & 10.5 \\
\hline & & (iii) & 31 to 35 & 29 & 07.6 \\
\hline & & (iv) & 36 to 40 & 58 & 15.2 \\
\hline & & (v) & 41 to 45 & 87 & 22.8 \\
\hline & & (vi) & 46 to 50 & 82 & 21.5 \\
\hline & & (vii) & 51 to 55 & 51 & 13.4 \\
\hline & & (viii) & 56 to 60 & 31 & 08.1 \\
\hline & & (ix) & Above 60 & 02 & 00.5 \\
\hline \multirow{2}{*}{6.} & \multirow{2}{*}{$\begin{array}{l}\text { Marital } \\
\text { status }\end{array}$} & (i) & Married & 380 & 99.5 \\
\hline & & (ii) & Unmarried & 002 & 00.5 \\
\hline
\end{tabular}

Table 3: Distribution of the respondents according to their demographic characteristics. of Rs.20,001 to Rs.50,000 (69.6\%). Majority of them were from age group of 36 to 50 years (59.5\%). Only two employees were unmarried. However, the relation of demographic variables with ORS and Burnout is beyond the scope of the present paper.

\section{Categorization of frequency of organizational role stress before and after the art of living programme}

The data were classified, tabulated, analysed and presented as per the specific objectives of the study. The data were analysed as per the scale of ORS scale of Pareek (1983). The obtained results of organizational role stress among the respondents are shown as Table 4 and Figure 1a and $1 \mathrm{~b}$. This table indicates that maximum of veterinarians $(72.46 \%)$ and paraveterinarians $(77.40 \%)$ had high Inter Role Distance. In case of Role Stagnation also, maximum of veterinarians $(57.63 \%)$ and paraveterinarians $(47.26 \%)$ were observed having high RS. The similar trend was observed in case of Role Expectation Conflict as maximum of veterinarians (43.6\%) and paraveterinarians $(45.2 \%)$ were in high category of REC. Looking to Role Erosion, minimum number of veterinarians $(21.2 \%)$ and paraveterinarians $(21.9 \%)$ were in high category. In case of role overload, $55.51 \%$ of veterinarians and $60.96 \%$ of paraveterinarians were under high category of role stress. Considering Role Isolation, nearly $40 \%$ of veterinarians and paraveterinarians were under high category. Nearly, half of the veterinarians $(50.42 \%)$ and paraveterinarians (47.26\%) were under high category of Personal Inadequacy. Very little number of the veterinarians (33\%) and paraveterinarians (28.7\%) were under high category of Self-Role Distance. In case of Role Ambiguity, a few veterinarians (39.83\%) and paraveterinarians (35.62\%) were under high category. Looking to resource inadequacy, maximum veterinarians $(61.02 \%)$ and paraveterinarians $(63.70 \%)$ were under high category. On completion of the intervention, the employees were again asked to respond to the same tools i.e., ORS scale and the MBIGS inventory. Considerable decreases in scores in high category for all the ORS factors are observed. IRD score reduced to $44.5 \%$ veterinarians and $46.6 \%$ paraveterinarians, respectively after the programme. In case of Role Stagnation, $37.3 \%$ of veterinary officers and $30.1 \%$ of paraveterinarians were in high category. The similar decrease trend was observed in case of Role Expectation Conflict as few of veterinarians $(16.5 \%)$ and paraveterinarians (15.0\%) were in high category of REC. Looking to Role Erosion, minimum number of veterinarians (16.5\%) and paraveterinarians (15.0\%) were in high category. In case of role overload, $36.8 \%$ of veterinarians and $39.7 \%$ of paraveterinarians were under high category of role stress. Considering Role Isolation, nearly $25.0 \%$ of veterinarians and paraveterinarians were under high category. Nearly, one third of the veterinarians $(38.1 \%)$ and paraveterinarians (32.2\%) were under high category of personal inadequacy. Very little number of the veterinarians (18.6\%) and paraveterinarians (21.2\%) were under high category of self-role distance.. In case of Role Ambiguity, a few veterinarians (24.6\%) and paraveterinarians (25.3\%) were under high category. Looking to resource inadequacy, maximum veterinarians $(41.1 \%)$ and paraveterinarians $(44.5 \%)$ were under high category. Thus, the total numbers of both veterinarians and paraveterinarians in each of the low, medium and high categories have changed after the Art of Living programme and the numbers in high category for both veterinarians and paraveterinarians were decreased for all the ORS. The trend indicates that programme was found to be effective in reducing ORS. Moreover, the mean scores for all ORS factors after the stress intervention programme are lesser than 
Citation: Soni SR, Vyas JM, Pestonjee DM, Kher HN, Thakkar KA, et al. (2015) Impact of the Art of Living Programme on Burnout and Organizational Role Stress among Animal Husbandry Personnel. J Psychiatry 18: 288 doi: 10.4172/2378-5756.1000288

Page 5 of 11

\begin{tabular}{|c|c|c|c|c|c|c|c|c|c|c|c|c|c|c|c|}
\hline \multirow{3}{*}{ ORS } & \multirow{3}{*}{$\begin{array}{c}\text { CA } \\
\mathbf{T}\end{array}$} & \multicolumn{4}{|c|}{ BEFORE } & \multicolumn{4}{|c|}{ AFTER } & \multicolumn{3}{|c|}{ MEAN } & \multirow{3}{*}{ S.E. } & \multirow{3}{*}{ 't' } & \multirow{3}{*}{$\begin{array}{c}P \\
\text { value }\end{array}$} \\
\hline & & \multicolumn{2}{|c|}{ Veterinary Officers } & \multicolumn{2}{|c|}{ Para-Vet. veterinarian } & \multicolumn{2}{|c|}{ Veterinary Officers } & \multicolumn{2}{|c|}{ Para-Vet. veterinarian } & \multirow{2}{*}{ Before } & \multirow{2}{*}{ After } & \multirow{2}{*}{ Diff } & & & \\
\hline & & Freq & $\%$ & Freq & $\%$ & Freq & $\%$ & Freq & $\%$ & & & & & & \\
\hline \multirow{3}{*}{ IRD } & L & 28 & 11.8 & 10 & 6.8 & 68 & 28.8 & 34 & 23.3 & \multirow{3}{*}{10.67} & \multirow{3}{*}{7.21} & \multirow{3}{*}{3.46} & \multirow{3}{*}{0.18} & \multirow{3}{*}{19.15} & \multirow{3}{*}{0.0037} \\
\hline & M & 37 & 15.6 & 23 & 15.7 & 63 & 26.7 & 44 & 30.1 & & & & & & \\
\hline & $\mathrm{H}$ & 171 & 72.4 & 113 & 77.4 & 105 & 44.5 & 68 & 46.6 & & & & & & \\
\hline \multirow{3}{*}{ RS } & L & 59 & 25.0 & 38 & 26.0 & 90 & 38.1 & 66 & 45.2 & \multirow{3}{*}{8.03} & \multirow{3}{*}{6.04} & & & & \\
\hline & $\mathrm{M}$ & 41 & 17.3 & 39 & 26.7 & 58 & 24.6 & 36 & 24.6 & & & 1.99 & 0.17 & 11.63 & 0.0082 \\
\hline & $\mathrm{H}$ & 136 & 57.6 & 69 & 47.2 & 88 & 37.3 & 44 & 30.1 & & & & & & \\
\hline & L & 67 & 28.3 & 36 & 24.6 & 101 & 42.8 & 57 & 39.0 & & & & & & \\
\hline REC & $\mathrm{M}$ & 66 & 27.9 & 44 & 30.1 & 74 & 31.3 & 46 & 31.5 & 6.47 & 5.00 & 1.46 & 0.17 & 8.35 & 0.0033 \\
\hline & $\mathrm{H}$ & 103 & 43.6 & 66 & 45.2 & 61 & 25.8 & 43 & 29.4 & & & & & & \\
\hline & L & 129 & 54.6 & 75 & 51.3 & 155 & 65.7 & 92 & 63.0 & & & & & & \\
\hline $\mathrm{RE}$ & $M$ & 57 & 24.1 & 39 & 26.7 & 42 & 17.8 & 32 & 21.9 & 8.14 & 6.85 & 1.29 & 0.17 & 7.35 & 0.0042 \\
\hline & $\mathrm{H}$ & 50 & 21.2 & 32 & 21.9 & 39 & 16.5 & 22 & 15.0 & & & & & & \\
\hline & L & 37 & 15.6 & 21 & 14.4 & 69 & 29.2 & 45 & 30.8 & & & & & & \\
\hline $\mathrm{RO}$ & $\mathrm{M}$ & 68 & 28.8 & 36 & 24.6 & 80 & 33.9 & 43 & 29.4 & 7.29 & 5.32 & 1.97 & 0.19 & 10.28 & 0.0039 \\
\hline & $\mathrm{H}$ & 131 & 55.5 & 89 & 60.9 & 87 & 36.8 & 58 & 39.7 & & & & & & \\
\hline & L & 85 & 36.0 & 49 & 33.5 & 125 & 52.9 & 75 & 51.3 & & & & & & \\
\hline RI & $M$ & 57 & 24.1 & 41 & 28.1 & 52 & 22.0 & 32 & 21.9 & 7.43 & 5.91 & 1.51 & 0.17 & 8.57 & 0.0063 \\
\hline & $\mathrm{H}$ & 94 & 39.8 & 56 & 38.3 & 59 & 25.0 & 39 & 26.7 & & & & & & \\
\hline & L & 41 & 17.3 & 22 & 15.1 & 65 & 27.5 & 44 & 30.1 & & & & & & \\
\hline PI & $\mathrm{M}$ & 76 & 32.2 & 55 & 37.6 & 81 & 34.3 & 55 & 37.6 & 7.82 & 6.29 & 1.52 & 0.19 & 7.83 & 0.0073 \\
\hline & $\mathrm{H}$ & 119 & 50.4 & 69 & 47.2 & 90 & 38.1 & 47 & 32.2 & & & & & & \\
\hline & L & 79 & 33.4 & 56 & 38.3 & 115 & 48.7 & 74 & 50.7 & & & & & & \\
\hline SRD & $M$ & 79 & 33.4 & 48 & 32.9 & 77 & 32.6 & 41 & 28.1 & 6.69 & 5.15 & 1.53 & 0.18 & 8.40 & 0.0068 \\
\hline & $\mathrm{H}$ & 78 & 33.0 & 42 & 28.7 & 44 & 18.6 & 31 & 21.2 & & & & & & \\
\hline & L & 58 & 24.6 & 46 & 31.5 & 85 & 36.0 & 68 & 46.6 & & & & & & \\
\hline $\mathrm{RA}$ & $M$ & 84 & 35.6 & 48 & 32.9 & 93 & 39.4 & 41 & 28.1 & 5.99 & 4.51 & 1.48 & 0.18 & 8.24 & 0.0078 \\
\hline & $\mathrm{H}$ & 94 & 39.8 & 52 & 35.6 & 58 & 24.6 & 37 & 25.3 & & & & & & \\
\hline & $\mathrm{L}$ & 48 & 20.3 & 25 & 17.1 & 81 & 34.3 & 47 & 32.2 & & & & & & \\
\hline RIN & $M$ & 44 & 18.6 & 28 & 19.2 & 58 & 24.6 & 34 & 23.3 & 8.96 & 6.89 & 2.07 & 0.18 & 11.40 & 0.0089 \\
\hline & $\mathrm{H}$ & 144 & 61.0 & 93 & 63.7 & 97 & 41.1 & 65 & 44.5 & & & & & & \\
\hline
\end{tabular}

Table 4: Results of ORS scale before and after the Art of Living programme and Test of significance by employing the formulae for calculation of percentage, average, mean, standard error, paired " $\mathrm{t}$ " test and 'P' value.

the mean scores before the programme. This difference is statistically significant at the $95 \%$ level $(\mathrm{p}<0.05)$.

\section{Categorisation of frequency of burnout sub-scale before and after the art of living programme}

The Art of Living programme was organized to know its impact on three sub-scales of burnout viz., Exhaustion (Ex), Cynicism (Cy) and Personal Efficacy (PE). Using mean difference score, ' $t$ ' values and ' $P$ ' values were calculated to compare the before and after score on each of the above three sub-scales. The obtained results of burnout are shown as Table 5 and Figure 2. Before the Art of Living programme, $49.15 \%$ of veterinary officers and $54.79 \%$ of paraveterinarians had low Exhaustion, whereas $38.98 \%$ of veterinary officers and $33.56 \%$ of paraveterinarians had medium Exhaustion. Remaining $11.86 \%$ of veterinary officers and $11.64 \%$ of paraveterinarians were under high category. After the Art of Living programme, the data were changed and $65.25 \%$ of veterinary officers and $67.81 \%$ of paraveterinarians were found in low category of Exhaustion, whereas $29.66 \%$ of veterinary officers and $25.34 \%$ of paraveterinarians had medium Exhaustion. 5\% of veterinary officers and $6.8 \%$ of paraveterinarians had high Exhaustion. The trend indicates that programme was found to be effective in reducing Exhaustion. Before the Art of Living programme, $50 \%$ of veterinary officers and $50.68 \%$ of paraveterinarians had medium Cynicism, whereas $35.17 \%$ of veterinary officers and $34.93 \%$ of paraveterinarians had low Cynicism. Remaining $14.83 \%$ of veterinary officers and $14.38 \%$ of paraveterinarians were under high category. After the Art of Living programme, the scores are considerably reduced. $47.46 \%$ of veterinary officers and $45.21 \%$ of paraveterinarians were found in low and medium category of Cynicism, respectively, whereas $43.22 \%$ of veterinary officers and $44.52 \%$ of paraveterinarians had medium and low Cynicism, respectively. The trend indicates that the programme was found to be effective in reducing Cynicism. Before the Art of Living programme, $46.19 \%$ of veterinary officers and $47.59 \%$ of paraveterinarians had high Professional Efficacy, whereas $35.17 \%$ of veterinary officers and 28.08\% of paraveterinarians had low Professional Efficacy. Remaining $18.64 \%$ of veterinary officers and $23.97 \%$ of paraveterinarians were under medium category. After the Art of Living programme, $65.68 \%$ of veterinary officers and $63.01 \%$ of paraveterinarians were found in high category of Professional Efficacy, whereas $19.07 \%$ of veterinary officers and $20.55 \%$ of paraveterinarians had medium Professional Efficacy. The trend indicates that the programme was found to be effective in increasing Professional Efficacy. The mean score for EX and CY after the intervention programme is lesser than the mean score before the programme whereas the mean score of $\mathrm{PE}$ is higher than before the programme. This difference is statistically significant at the $95 \%$ level $(\mathrm{p}<0.05)$. 
Citation: Soni SR, Vyas JM, Pestonjee DM, Kher HN, Thakkar KA, et al. (2015) Impact of the Art of Living Programme on Burnout and Organizational Role Stress among Animal Husbandry Personnel. J Psychiatry 18: 288 doi: 10.4172/2378-5756.1000288
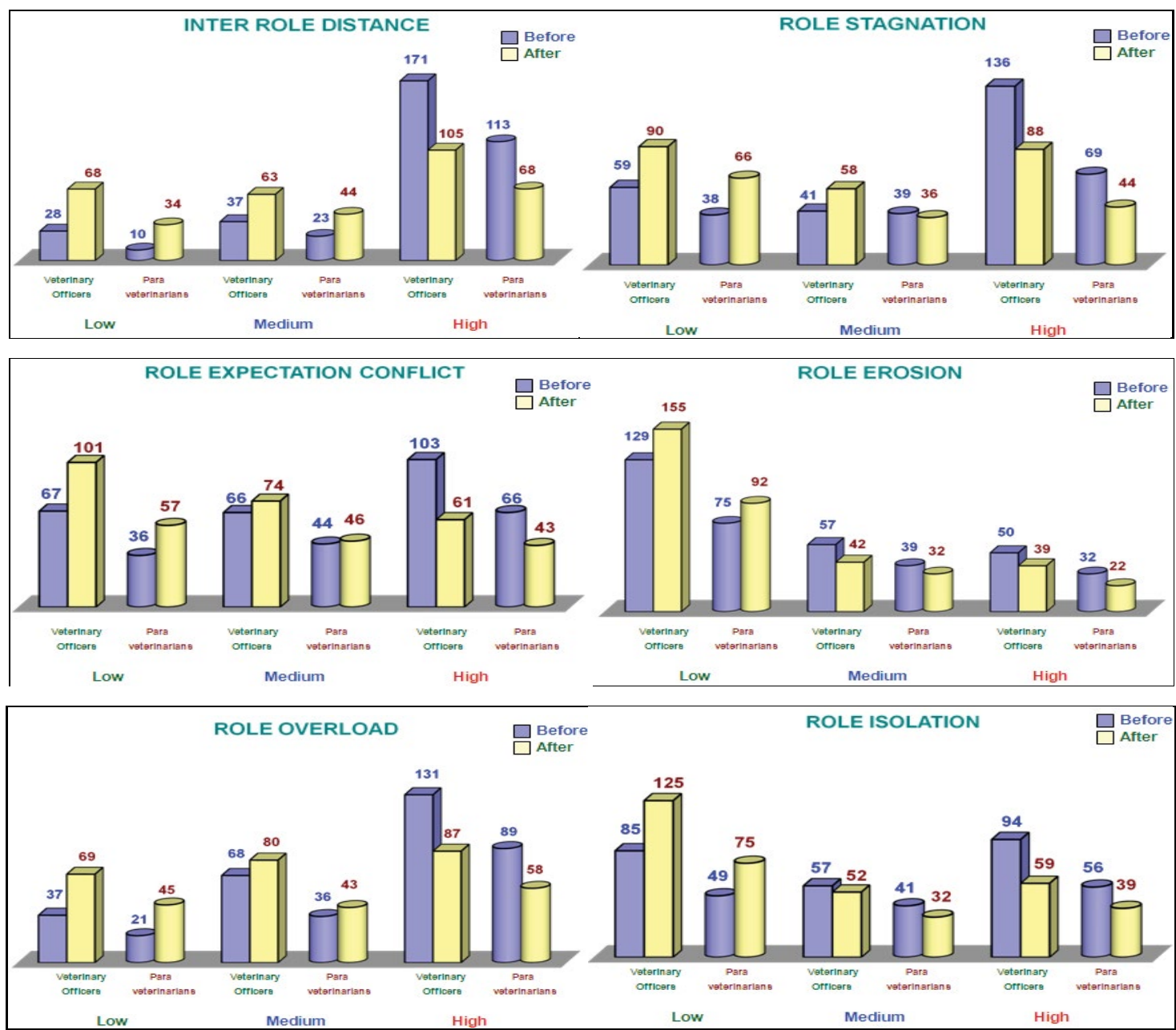

Figure 1(a): ORS scale scores before and after the Art of Living program
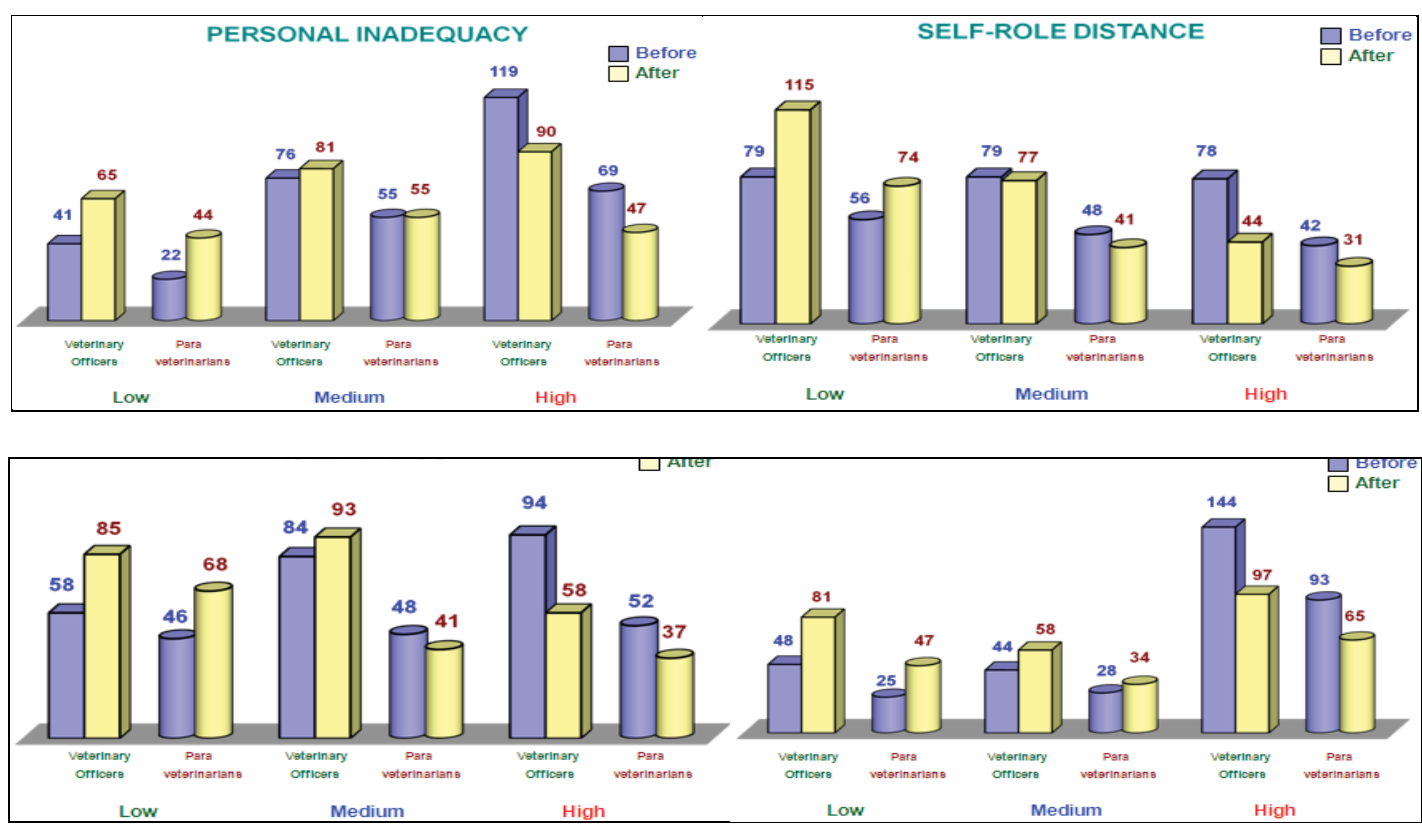

Figure 1(b): ORS scale scores before and after the Art of Living programme. 
Citation: Soni SR, Vyas JM, Pestonjee DM, Kher HN, Thakkar KA, et al. (2015) Impact of the Art of Living Programme on Burnout and Organizational Role Stress among Animal Husbandry Personnel. J Psychiatry 18: 288 doi: 10.4172/2378-5756.1000288

Page 7 of 11

\begin{tabular}{|c|c|c|c|c|c|c|c|c|c|c|c|c|c|c|c|}
\hline \multirow{3}{*}{$\begin{array}{c}\text { Burn } \\
\text { out }\end{array}$} & \multirow{3}{*}{ Cat } & \multicolumn{4}{|c|}{ BEFORE } & \multicolumn{4}{|c|}{ AFTER } & \multicolumn{3}{|c|}{ MEAN } & \multirow{3}{*}{ S.E. } & \multirow{3}{*}{ 't' } & \multirow{3}{*}{$P$ value } \\
\hline & & \multicolumn{2}{|c|}{ Veterinary Officers } & \multicolumn{2}{|c|}{ Para veterinarian } & \multicolumn{2}{|c|}{ Veterinary Officers } & \multicolumn{2}{|c|}{ Para veterinarian } & \multirow{2}{*}{ Before } & \multirow{2}{*}{ After } & \multirow{2}{*}{ Diff } & & & \\
\hline & & Freq & $\%$ & Freq & $\%$ & Freq & $\%$ & Freq & $\%$ & & & & & & \\
\hline \multirow{3}{*}{ EX } & L & 116 & 49.1 & 80 & 54.8 & 154 & 65.2 & 99 & 67.8 & \multirow{3}{*}{8.14} & \multirow{3}{*}{5.98} & \multirow{3}{*}{2.15} & \multirow{3}{*}{0.24} & \multirow{3}{*}{8.86} & \multirow{3}{*}{0.0097} \\
\hline & $M$ & 92 & 38.9 & 49 & 33.5 & 70 & 29.6 & 37 & 25.3 & & & & & & \\
\hline & $\mathrm{H}$ & 28 & 11.8 & 17 & 11.6 & 12 & 5.08 & 10 & 6.8 & & & & & & \\
\hline \multirow{3}{*}{$\mathrm{CY}$} & L & 83 & 35.1 & 51 & 34.9 & 112 & 47.4 & 65 & 44.5 & \multirow{3}{*}{7.30} & \multirow{3}{*}{5.88} & \multirow{3}{*}{1.41} & \multirow{3}{*}{0.22} & \multirow{3}{*}{6.36} & \multirow{3}{*}{0.0082} \\
\hline & $M$ & 118 & 50.0 & 74 & 50.7 & 102 & 43.2 & 66 & 45.2 & & & & & & \\
\hline & $\mathrm{H}$ & 35 & 14.3 & 21 & 14.4 & 22 & 9.3 & 15 & 10.2 & & & & & & \\
\hline \multirow{3}{*}{ PE } & L & 83 & 35.7 & 41 & 28.1 & 36 & 15.2 & 24 & 16.4 & \multirow{3}{*}{25.26} & \multirow{3}{*}{29.13} & \multirow{3}{*}{-3.8} & \multirow{3}{*}{0.47} & \multirow{3}{*}{8.24} & \\
\hline & $M$ & 44 & 18.6 & 35 & 23.9 & 45 & 19.0 & 30 & 20.5 & & & & & & 0.0069 \\
\hline & $\mathrm{H}$ & 109 & 46.1 & 70 & 47.9 & 155 & 65.6 & 92 & 63.0 & & & & & & \\
\hline
\end{tabular}

Table 5: Results of Burnout scale before and after the Art of Living program and test of significance by employing the formulae for calculation of percentage, average, mean, standard error, paired " $\mathrm{t}$ " test and ' $\mathrm{P}$ ' value.
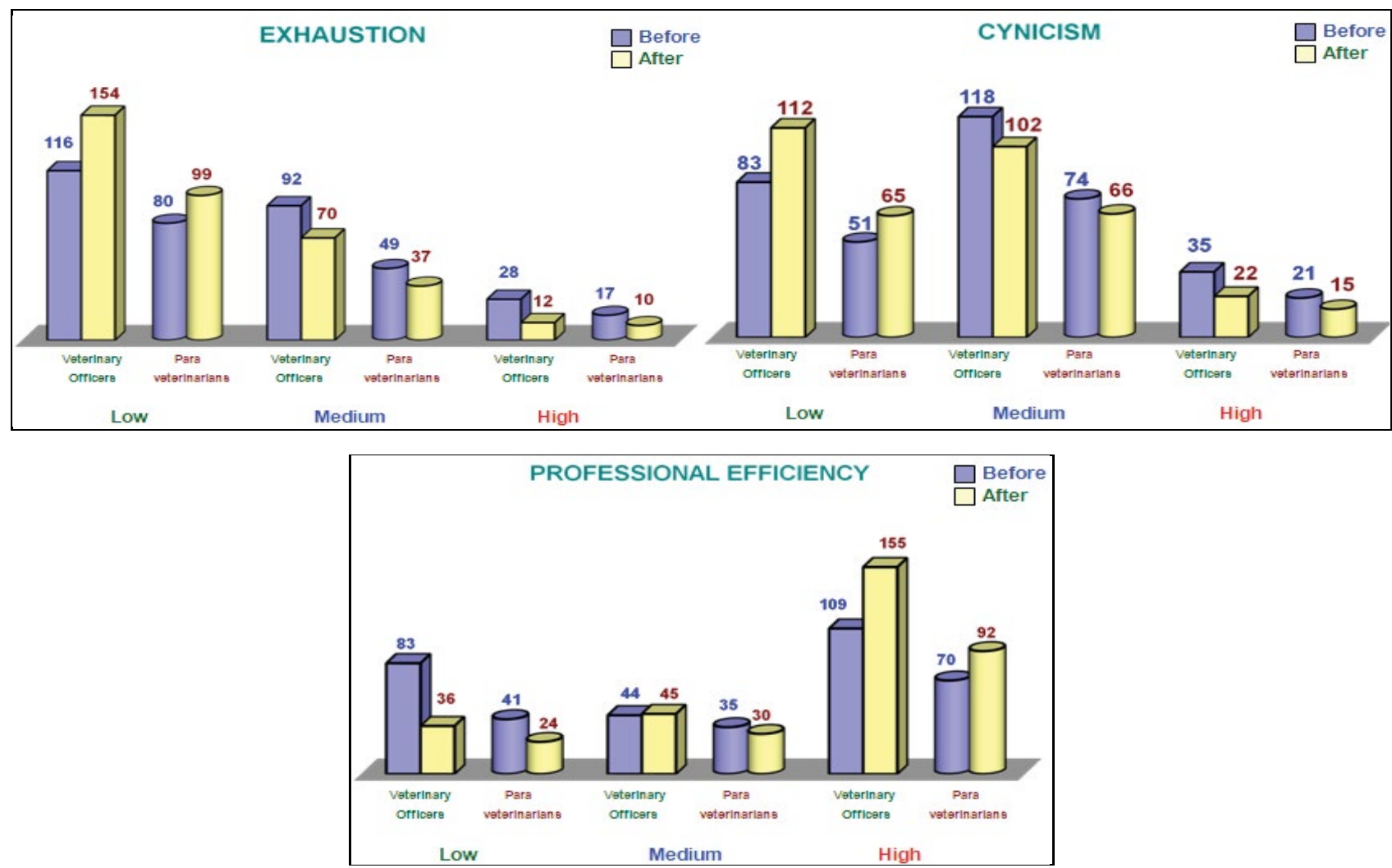

Figure 2: Burnout scale scores before and after the Art of Living programme.

\section{Test of significance for organizational role stress factors and burnout}

The attempt was made to know the impact of the Art of Living programme in each of the ten ORS factors and Burnout sub-scales. Paired ' $t$ ' was applied for knowing impact of the intervention. The data in this regard is presented in Table 4. The significant ' $t$ ' values indicate that the programme had significant impact in all the ORS viz., IRD (19.153), RS (11.635), REC (8.355), RE (7.354), RO (10.288), RI (8.579), PI (7.831), SRD (8.409), RA (8.242) and RIN (11.402). Further, the maximum mean difference was observed in IRD (3.463) followed by RIN (2.073) and RS (1.992). The mean difference in case of RO, SRD and PI was $1.974,1.539$ and 1.524 , respectively. The lower mean difference was observed in case of RI (1.513), RA (1.482), REC
(1.469) and RE (1.293). It can be thus, concluded that the Art of Living programme was found effective in reducing ORS of the respondents.

The Art of Living programme was organized to know its impact on three sub-scales of burnout viz., exhaustion, cynicism and personal efficacy. Using mean difference score, ' $t$ ' value was calculated to compare the before and after score on each of the above three subscales. The results are given in Table 5 . It can be observed that ' $t$ ' values in case of exhaustion, cynicism and personal efficacy. Were 8.868, 6.363 and 8.242 , respectively. All the ' $t$ ' values were found statistically highly significant. The mean difference score in case of exhaustion and cynicism was 2.157 and 1.414, whereas in case of personal efficacy, it was -3.869. Thus, the Art of Living programme has created its significant impact in increasing personal efficacy and decreasing exhaustion and 
cynicism. In view of above discussion, the hypothesis 1.2.2 is therefore, rejected.

\section{Relationship among organizational role stress factors and burnout sub-scales}

The major thrust of the present investigation is on ORS and burnout among veterinarians and paraveterinarians. It is therefore, important to know the relationship of ORS factors with three subscales of Burnout. The correlation co-efficient (' $r$ ') was used to ascertain the relationship. The data on relational analysis is presented in Table 6 . It can be seen that all the stress factors viz., IRD (0.279), RS (0.319), REC (0.217), RE (0.239), RO (0.309), RI (0.211), PI (0.280), SRD (0.337), RA (0.263) and RIN (0.250) established positively significant relationship with EX at 0.01 level of significance. Similarly, all the ORS factors established positively significant relationship with CY either at 0.05 or at 0.01 level of significance. Above discussion and table values indicate that hypothesis 1.2.1 is rejected in case of EX and CY sub-scales of burnout. On the other hand, all the ORS factors have failed to establish significant relationship with PE. Hence, the null hypothesis is accepted in case of personal efficacy dimensions of burnout. Thus, it can be said that all the ORS factors have positively contributed in increasing EX and $\mathrm{CY}$.

\section{Discussion}

\section{Status of organizational role stress and burnout among} animal husbandry personnel before intervention

Data in Table 4 indicate that about $51 \%$ of the respondents fell in the high ORS category, while $28 \%$ and $21 \%$ respectively fell in the medium and low ORS categories. Nearly $80 \%$ of the veterinarians and paraveterinarians fell under the medium to high range of organizational role stress. Bano and Jha reported that there were moderate levels of role stress among the employees in public and private sectors [18]. Moderate to high stress levels were observed among the Belgian veterinary surgeons [19]. Gardner and Hini also observed moderate stress levels among veterinarians [14]. Rejula et al. reported that $73 \%$ of Finnish veterinary surgeons studied, perceived the feeling of 'very stressed' [20]. Elkins and Elkins presented similar results [21]. The results of the present study confirm that the veterinary profession was inherently stressful.

On the basis of forgoing analysis, majority of veterinarians and paraveterinarians fall under "high" category when it comes to role stress factors like IRD, RS, REC, RO, PI, RIN and RA. This shows that majority of the employees are under stress due to conflict that is arising between their professional life and non-work life. They also feel that their abilities are being misused or under used in their job. They become restless because of the conflicting expectations of their seniors, juniors and peers. This also shows that the demands on majority of the employees are much more than what they can tolerate. Role overload develops when the role occupant feels that there are too many expectations from significant others in his role set. It is more likely to occur when the role occupant lacks power, where there are large variations in the expected output [22]. Role overload influence work quality and results in the feeling of not being able to finish an ordinary day's work in one day [23]. Similar findings were made by Hansez et al. who observed that long working hours were a source of stress inherent to the situation of veterinary surgeons. Long working hours as a potential cause of stress among veterinarians was also reported by Elkins and Elkins and Gardner and Hini [14,21]. Harling et al. also observed that long working time was a significant contributor to work stress among veterinarians in Germany [24].

Resource inadequacy referred to the non-availability of resources needed for effective role performance. A high score on PI and RIN shows that majority of the employees feel that they do not have sufficient skills and sufficient/adequate resources to perform their duties effectively. This shows that there is high priority to boost the motivation of the employees by providing them with sufficient training and resources. Inter Role Distance arises because of conflict between his /her organizational role and other roles. The results of the present study indicated that veterinarians and paraveterinarians experienced stress due to conflict between their organizational role and other roles in their life. Role stagnation referred to the perception of the respondent that there were fewer opportunities for learning and growth in his or her organizational role. Role stagnation has been reported to be a feeling of being stuck in the same role. In role stagnation, the changing demands of the role may produce stress. Gohar et al. also reported that role stagnation has significant impact on dimensions of stress and burnout [25]. Self role distance referred to the conflict of a respondent's values and self-concepts with the requirements of the organizational role. A low score on RE shows that the employees have good working environment where there is no conflict among the employees due to the nature of work. The overall results in the ORS scale indicate that employees are having high role stress and need immediate interventions to mitigate the adverse effect of the role stress.

Burnout is common in physicians, affecting an estimated 25-75\% in previous studies $[26,27]$. Several studies have also examined burnout in veterinarians [28]. A 1992 study reported $67 \%$ of female and $53 \%$ of male U.S. veterinarians were considered at high risk of burnout using a self-diagnosis burnout scale [29], although other veterinary studies have found burnout ranged between 15 and 40\% [30]. As per our study results, in case of burnout, existence of majority of employees in the low category for the "exhaustion" factor indicates that they are experiencing a low fatigue which is a healthy sign. In terms of their attitude to work, majority of the employees are in "medium" category which is a cautioning sign. If measures are taken properly there is a scope to turn their energies positively towards their profession, otherwise, they can even turn completely indifferent towards their work. Looking to Professional Efficacy, majority of employees are in "high" category of Personal Efficacy which shows that the employees stress levels have not reached the peak level. Research indicates Personal Efficacy may be reduced when there is a lack of social support within the work environment $[31,32]$ or there is a lack of opportunity for staff to engage in professional development. This then results in people feeling less competent, and inadequately prepared to

\begin{tabular}{|c|c|c|c|c|c|c|c|c|c|c|}
\hline & \multicolumn{10}{|c|}{ CORRELATIONS } \\
\hline & IRD & RS & REC & RE & RO & $\mathbf{R} \mathbf{I}$ & PI & SRD & RA & RIN \\
\hline EX & 0.279 & 0.319 & 0.217 & 0.239 & 0.309 & 0.211 & 0.280 & 0.337 & 0.263 & 0.250 \\
\hline CY & 0.129 & 0.151 & 0.171 & 0.149 & 0.101 & 0.197 & 0.174 & 0.233 & 0.214 & 0.157 \\
\hline $\mathrm{PE}$ & 0.042 & 0.048 & -0.094 & 0.027 & -0.007 & 0.026 & 0.059 & -0.071 & -0.068 & 0.028 \\
\hline
\end{tabular}

Table 6: Relationship among organizational role stressors and burnout sub-scales by employing the formula for calculation of Pearson's product moment correlation coefficient. 
help clients. Cynicism may result when clinics do not have effective communication strategies including effectively run staff meetings, internal newsletters, or opportunities for employees to participate in the development of standardized clinic policies and procedures. In that case, employees may disengage from the work environment. Research has shown improving communication strategies through changing the format in which information is shared, providing timely information, and involving staff in the dissemination of information has had positive effects on burnout and work engagement [33]. Our results indicate that veterinarians and paraveterinarians are having moderate level of cynicism and need certain interventions to mitigate the possibilities of adverse effect of the burnout.

\section{Intervention (Art of Living Program)}

The Art of Living programs are organized by the Art of Living Foundation, one of the largest international nongovernment organizations. It is a non-profitable educational and humanitarian foundation with a special consulting status in the Economic and Social Council of the United Nations. One of key characteristics of the educational programs offered by the Foundation is giving practical knowledge, techniques and skills that help people cope with stress and stressful situations, remove their influences and handle more efficiently with different tasks and demands in daily life, while at the same time improving health and achieving better quality of life. So far more than 20 million people from more than 151 countries participated in their programs.

The Art of Living programs include learning and performing special breathing techniques. The methodology is based on the paradigm of the mind/body medicine which says that a person's emotional and psychological state directly influences the functioning of numerous processes in the person's body, immunity and endocrine systems, functioning of the brain as well as the ability of responding to different circumstances, thus also on the quality and length of life. The breathing techniques in the stress intervention programme that the veterinarians and paraveterinarians participated in, that is, the Art of Living program, included:

- The three stages of pranayama breathing, which maximises oxygen intake and energizes the person. This breathing technique opens the lungs and maximises the absorption of prana (the vital life energy in the body). It recharges the cells, keeping a person energized, with resilient health and brilliant clarity of mind.

- The breathing technique bhastrika, or bellows breath which involved short, forceful breathing, and is followed by a short period of rest, thereby making one mentally alert yet emotionally calm.

- The Sudarshan Kriya which is the revitalizing breathing technique and relieves stress at the physical, mental and emotional levels by neutralizing toxins. This unique breathing technique eliminates stress, fatigue and negative emotions such as anger, frustration and depression, leaving you calm yet energized, focused yet relaxed.

The participants are directed towards internal locus of control, reduced anxiety, management of stress and its effects, achieving better personality strength, improvement of interpersonal relations, selfimage and self-respect, increase of personal competence and to higher level of satisfaction with life. During the program the participants also learn special physical exercises that increase physical strength, adaptability and immunity and have beneficial effect on the nervous system [34].

\section{Impact of intervention program on ORS and Burnout among animal husbandry personnel}

Yoga and Meditation based interventions are slowly making their way into workplace settings. Studies indicate that practice of Meditation, Yoga and Breathing Techniques reduces psychological and physiologic response to stress factors and reductions in elevations in elevated cortisol (stress hormone) levels [35-37]. Research also shows a more coherent and integrated style of brain functioning, evidenced by EEG imaging, which is associated with lower stress reactivity [38] Considerable reductions in psychological distress, including anxiety and depression, which were associated with decreased blood pressure among college students practicing Meditation [39]. A 2003 study revealed significantly higher impact of exercise with a mindful-based component verses aerobic exercise without mindfulness with a $\mathrm{P}<.01$ [40]. Significant levels of reduction in depression was observed in 25 Indian adults with $\mathrm{P}<.05$ within 15 days using an intervention of yoga, meditation and breathing techniques [41]. Since relaxation seems to enhance regular interventions which appear to be working on stress and anxiety, looking into research on the impact of meditation on stress and anxiety in the workplace makes sense. Stress-free employees perform better, work harder, feel happier and have a long term commitment to the organization as compared to their counterparts.

On the basis of our study results, it can be stated that maximum veterinarians and paraveterinarians had lowered their scores in high IRD, RS, REC, RO, PI, RIN and RA after the Art of Living programme. Looking to $\mathrm{RE}$, maximum veterinarians and paraveterinarians were further lowered their scores in low category after the intervention. Almost equal distribution each in low, medium and high categories of SRD was observed before the Art of Living programme in both the categories of the respondents were placed in low category of SRD after the intervention. This indicates that the Art of Living programme has decreased the organizational role stress factors. Looking to Exhaustion sub-scale, the percentage of both veterinarians (49\%) and paraveterinarians (55\%) in low category has increased to $65 \%$ and $68 \%$, respectively after intervention. Similar trend was observed in case of Cynicism and total number of both veterinarians and paraveterinarians in low category had increased after intervention. Personal Efficacy had increased to considerable extent from $46 \%$ to $66 \%$ in case of veterinarians and $48 \%$ to $63 \%$ in case of paraveterinarians after intervention. Significant difference between pre and post score was also observed in case of all three burnout sub scales viz., EX, CY and PE. The breathing techniques in the Art of Living program helped the veterinarians and paraveterinarians to reduce their stress levels. The overwhelming response of all the veterinarians and paraveterinarians in the investigation was that they felt calmer and more relaxed after the intervention. The benefits of the Art of Living program in the current study may be compared to previous studies that have emphasised the advantages of breathing techniques to control stress, reduce tension and anxiety and feel relaxed and in control [42-49]. It was confirmed that a very good way to relax is to take several deep breaths and exhale slowly when you feel stress building up.

We have also collected qualitative data by obtaining written experiences about the impact of the Art of Living programme on the different aspect of life by the respondents. It appears from the experiences gained by the respondents that the programme has affected the respondents in manifolds. The impact of the course does not remain up to the organisational role stress and burnout. It spreads over the entire life activity of the respondents and impact on the physical, mental, organisational, social and spiritual aspect of life. With these 
Citation: Soni SR, Vyas JM, Pestonjee DM, Kher HN, Thakkar KA, et al. (2015) Impact of the Art of Living Programme on Burnout and Organizational Role Stress among Animal Husbandry Personnel. J Psychiatry 18: 288 doi: 10.4172/2378-5756.1000288

Page 10 of 11

impacts, the programme became the means for elimination of stress and burnout of work life and non-work life. The participants felt the psychosomatic benefits of the course and relieved from the multiple diseases.

\section{Conclusions}

On the basis of forgoing discussion it can be concluded that maximum veterinarians and paraveterinarians had high IRD, RS, REC, RO, PI, RIN and RA before the Art of Living programme. However, the percentage of the respondents in high category has decreased to a considerable extent after the Art of Living programme. Significant difference between pre- and post score was also observed in case all of the three burnout scales viz., EX, CY and PE. Looking to the overall findings of the quantitative and qualitative data, it is concluded that majority of the veterinarians and paraveterinarians are suffering from the organisational role stress. But, it has limited effects on their burnout. Majority of the respondents do not suffer burnout. The analysis of quantitative data provides substantial evidences of having positive impact of the Art of Living programme on the organisational role stress and burnout. The qualitative data provide sufficient evidences of reducing organisational role stress as well as non work stress. Not only that, but also it affects positively on their holistic well being covering body, mind and wellbeing of the participants. The findings lead us to the unmistakable conclusion that Art of Living programmes (when conducted under proper environment) have a salutary beneficial impact on organizational wellbeing of the individual. This study suggests that health and human resource practitioners should use/recommend this intervention strongly to reduce the occupational stress and burnout and to maximize the human potential.

\section{References}

1. Agrawal N (1984) Application of Job Characteristic Approach in Management of Organisational Stress. FPM Written Comprehensive Examination. Paper. OB Area. IIM. Ahmedabad.

2. Pestonjee DM (1992) Stress and Coping: The Indian Experience. $2^{\text {nd }}$ edition, Sage Publication, New Delhi.

3. Pestonjee DM, Singh UB (1981) Locus of control as a moderator of role stresssatisfaction relationship. Indian Institute of Management, Ahmedabad.

4. Pestonjee DM, Azeem SM (2001) Study of organisational role stress in relation to job burnout among University Teachers. Working Paper No. 2001-04-02. Indian Institute of Management, Ahmedabad.1-57.

5. Birmingham JA (1985) Job Satisfaction and Burnout among Minnesota Teachers. Ph.D. Dissertation, University of Minnesota, Dissertation Abstracts International 45-08 2318-A

6. Whitehead JT (1986) Job burnout and job satisfaction among probation managers. J Criminal Justice 14: 25-35.

7. Turnipseed DL (1987) Burnout among hospice nurses: An empirical assessment. In: Stress and Burnout among Providers Caring for the Terminally III and their Families edited by L. Finn-PRdis., New York, The Haworth Press105-119.

8. Malhotra R (1989) A study of burnout and job satisfaction among architect of Chandigarh. M.Ed. Dissertation, Punjab University, Chandigarh.

9. Basi SK (1990) A study of teaching competency of language teachers in relation to their job satisfaction, locus of control and professional burnout. Ph.D. Thesis in Education, Punjab University, Chandigarh.

10. Das M (1990) Extent of burnout in teachers. Expt. in Edn 18: 174-178.

11. Gupta R, Dang R (1993) Burnout among teachers. Indian J Appl Psychol 27: 80-83.

12. Dasgupta H, Kumar S (2009) Role Stress among Doctors Working in a Government Hospital in Shimla (India). European J Soc Sci 9.

13. Sharma NH, Sen S, Singh A, Bhardwaj NK, Kochupillai V, et al. (2003)
Sudarshan kriya practitioners exhibit better antioxidant status and lower blood lactate levels. Biological Psychology. 63: 281-291.

14. Gardner DH, Hini D (2006) Work-related stress in the veterinary profession in New Zealand. New Zealand Veterinary Journal 54: 119-124.

15. Kerlinger FN (1986) Foundations of Behavioural Research, 3rd Edn. New York: Holt, Rinehart and Winston. Chapters 22, 23, 24 (Especially the Sections on Advantages and Disadvantages).

16. Pareek U (1983) Organisational Role Stress Scale. ORS Scale Booklet, Answer sheet and Manual. Ahmedabad: Navin Publications.

17. Maslach C , Jackson S, Leiter MP (1996) Maslach Burnout Inventory Manual, $3^{\text {rd }}$ Ed., CPP, Inc., Mountain view, California.

18. Bano B, Jha RK (2012) Organizational role stress among public and private sector employees: A comparative study. The Lahore Journal of Business 30 : 23-36.

19. Hansez I, Schins F, Rollin F (2008) Occupational stress, work-home interference and burnout among Belgian veterinary practitioners. Ir Vet J 61: 233-241.

20. Reijula K, Rasanen K, Hamalainen, M, Juntunen K (2003) Work environment and occupational health of Finish veterinairans. American Journal of Industrial Medicine 44: 46-57.

21. Elkins AD, Elkins JR (1987) Professional burnout among U.S. veterinarians: how serious a problem? Veterinary Medicine 82: 1245-1250.

22. Pareek U (1993) Role stress and coping: A framework In: Studies in Organisational Role Stress and Coping edited by Pareek, U. and Pestonjee, D.M., Rawat Publications, Jaipur: 1-40.

23. Kahn RL (1964) Organizational Stress: Studies in Role Conflict and Ambiguity. John Wiley and Sons Ltd.Canada.

24. Harling M, Strehmel P, Schablon A, Nienhaus A (2009) Psychosocial stress, demoralization and the consumption of tobacco, alcohol and medical drugs by veterinarians. J Occup Med Toxicol 40: 4.

25. Gohar S, Abbas, Roger A, Ali M, Adullah (2012) Impact of Organizational Role Stressors on Faculty Stress and Burnout. Paper presented in 4ème colloque international (iseor - aom), France, June 5 to 6 .

26. Fahrenkopf AM, Sectish TC, Barger LK (2008) Rates of medication errors among depressed and burnt out residents: prospective cohort study. BMJ 336 488-491.

27. Shanafelt TD, Bradley KA, Wipf JE, Back AL (2002) Burnout and self-reported patient care in an internal medicine residency program. Ann Intern Med 136: 358-67.

28. Hatch P, Winefield H, Christie B, Lievaart J (2011) Workplace stress, mental health, and burnout of veterinarians in Australia. Aust Vet J 89: 460-468.

29. Elkins AD, Kearney M (1992) Professional burnout among female veterinarians in the United States. J Am Vet Med Assoc 200: 604-608.

30. Shanafelt TD, Balch CM, Bechamps G (2010) Burnout and medical errors among American Surgeons. Ann Surg 251: 995-1000.

31. Maslach C, Goldberg J (1998) Prevention of burnout: New perspectives. Applied \& Preventive Psychology 7: 63-74

32. Schaufeli WB, Greenglass ER (2001) Introduction to special issue on burnout and health. Psychology \& Health 16: 501-510.

33. Maslach C, Leiter MP (1997) The truth about burnout: How organizations cause personal stress and what to do about it. San Francisco, CA: Jossey-Bass.

34. Janakiramaiah N, Gangadhar BN (2000) Anti Depressant Efficacy of Sudarshan Kriya Yoga in Melancholia-a randomized comparison with ETC and Imipramine. Journal of Affective Disorders. 57: 255-259.

35. Barnes VA, Treiber FA, Davis H (2001) Impact of Transcendental Meditation on cardiovascular function at rest and during acute stress in adolescents with high normal blood pressure. J Psychosom Res 51: 597-605.

36. MacLean CR, Walton KG, Wenneberg SR (1997) Effects of the Transcendenta Meditation programm on adaptive mechanisma: changes in hormone levels and response to stress after 4 months of practice. Psychoneuroendocrinology 22: $277-95$. 
Citation: Soni SR, Vyas JM, Pestonjee DM, Kher HN, Thakkar KA, et al. (2015) Impact of the Art of Living Programme on Burnout and Organizational Role Stress among Animal Husbandry Personnel. J Psychiatry 18: 288 doi: 10.4172/2378-5756.1000288

Page 11 of 11

37. Walton KG, Schneider RH, Nidich S (2004) Review of controlled research on the Transecendental Meditation program and cardiovascular diesease. Risk factors, morbidity, and mortality. Cardiol Rev12: 262-6.

38. Travis F, Haaga DA, Hagelin J (2009) Effects of Transcendental meditation practice on brain functioning and stress reactivity in college students. Int $\mathrm{J}$ Psychophysical 71: 170-6.

39. Nidich SI, Rainforth MV, Haaga DA (2009) A randomized controlled trial on effects of the Transcendental Meditation programme on blood pressure, psychological distress, and coping in young adults. Am J Hypertens 22: 1326-1331.

40. Netz Y, Lidor R (2003) Mood Alterations in Mindful Versus Aerobic Exercise Modes. J Psychol 137: 405-419.

41. Mishra M, Sinha RK (2001) Effect of Yogic Practices on Depression and Anxiety. J Project Psychol and Mental Health 8: 23-27.

42. Fried $R$ (1993) The role of respiration in stress and stress control In: Lehrer, $P$. M. \& Woolfolk, R. L. (eds). Principles and practice of stress management. New York: Guildford Press.
43. Patel C (1989) The complete guide to stress management. London: Macdonald $\&$ Co.Ltd.

44. Schafer W (1996) Stress management for wellness. Harcourt: Brace College Publishers.

45. Katzel M (1968) Expectations and Dropouts in Schools of Nursing J Appl Psychol 52: 154-157.

46. Maslach C, Jackson S (1986) Maslach Burnout Inventory, (2ndedn). Consulting Psychologist Press, Palo Alto, CA, U.S.A.

47. Maslach C (2003) Burnout: the cost of caring, Malor Books, ISBN=9781883536350.

48. Panagopoulou E, Montgomery A, Benos A (2006) Burnout in internal medicine physicians: Differences between residents and specialists. Eur J Int Med 17: 195-2000.

49. Pareek U (1993) Making Organisational Roles Effective. TATA McGraw-Hil Publ. Co. Ltd., New Delhi. 68-70. 